\title{
Multiple recurrent follicular dendritic cell sarcoma: A case report
}

\author{
LARA SCHORN $^{1}$, JULIAN LOMMEN $^{1}$, RITA DEPPRICH ${ }^{1}$, NORBERT KÜBLER ${ }^{1}$, MAJEED RANA $^{1}$, \\ CARINA HEYDT $^{2}$, PHILIPP LOHNEIS ${ }^{2}$, PETER KAISER ${ }^{3}$ and CHRISTOPH SPROLL ${ }^{1}$ \\ ${ }^{1}$ Department of Oral and Maxillofacial Surgery, Medical Faculty, \\ Heinrich-Heine-University and University Hospital Düsseldorf, D-40225 Düsseldorf; ${ }^{2}$ Department of Pathology, \\ Medical Faculty, University Hospital Cologne, D-50937 Cologne; ${ }^{3}$ Department of Pathology, Medical Faculty, \\ Heinrich-Heine-University and University Hospital Düsseldorf, D-40225 Düsseldorf, Germany
}

Received July 15, 2019; Accepted May 26, 2020

DOI: $10.3892 / \mathrm{mco} .2020 .2093$

\begin{abstract}
Tumors of the follicular dendritic cells (FDC-Sarcoma) represent a rare entity with only about 200 cases reported worldwide. The majority $(60 \%)$ of cases arise primarily in cervical, abdominal or axillar lymph nodes, but extra nodal origin from secondary lymphatic tissue like the tonsils, Waldeyer's ring or MALT is also common (40\%). The current report presents a characteristic course of a cervical FDC-Sarcoma, with its challenges in establishing the initial diagnosis and the struggle for therapeutic options. The FDC-Sarcoma presented recurrently for four times. Three different university hospitals in Germany were involved in the patients' treatment. Due to the patients' refusal, no adjuvant therapy was applied. In the end, a neck dissection was performed. The patient was closely followed up and has been recurrence-free for 10 years. This case suggests operative resection in combination with a neck dissection as a curative therapy for FDC-Sarcoma of the head and neck.
\end{abstract}

\section{Introduction}

Follicular dendritic cells are, due to their function of presenting and retaining antigens, important contributors to memory B-Cell maturation during germinal centre reaction (GCR) (1). They organise B-Cell homeostasis and immune response in secondary lymphoid organs and seem to be the connection between innate and adaptive (B cell) response (2,3). B-Cell migration from follicles and competent humoral immune response are dependent on Follicular Dendritic Cells (4-6). They secrete CXCL13 chemokine for B-Cell follicle homing

Correspondence to: Dr Julian Lommen, Department of Oral and Maxillofacial Surgery, Medical Faculty, Heinrich-Heine-University and University Hospital Düsseldorf, Moorenstr. 5, D-40225 Düsseldorf, Germany

E-mail: julian.lommen@med.uni-duesseldorf.de

Key words: follicular dendritic cell sarcoma, head and face, oncology and built a scaffold for B-cell migration $(7,8)$. Cellular mechanisms of Follicular Dendritic Cells are subject to research and lymph node FDC progenitor cells are still unknown. Research is especially difficult considering the fact that FDCs work in delicate 3D networks subsequent to pathogen exposition, limiting vitro examination in particular $(2,9,10)$. The extremely rare neoplasm follicular dendritic cell sarcoma (FDCS) was first characterised by Monda et al (11) in 1986. Until today about 120 cases of FDCS of the head and neck region have been reported (12). The majority (60\%) arises primarily in cervical, abdominal or axillar lymph nodes, but also extra-nodal origin from secondary lymphatic tissue like the tonsils, Waldeyer's ring or MALT is not uncommon (40\%) (13). Final diagnosis of FDCS can only be established by immunohistochemical profiling. FDCS usually proves positive for CD21, CD23, CD35, KI-M4p, clusterin, Claudin 4, CXCL 13 and Ki-FDC1p, and in some cases for vimentin, S-100 protein, CD68, and specific muscle actin (SMA) $(12,14,15)$. Often further pathological, electron microscope and cytochemical analyses are required. Clinically, FDCS shows low to intermediate malignant potential and a local recurrence rate of $40 \%$. Distant metastasis occurs in $25 \%$ of cases, most often in the lungs, liver, peritoneum, and lymph nodes resulting in a mortality rate of $16.7 \%$ (14). Because the origin of follicular dendritic cells is uncertain, therapy of the FDCS varies. Krautler et al (16), found that FDCs are stromal in origin. In contrast to other dendritic cells, which are hematopoietic, they develop from mural cells (16) but opinions in literature vary $(5,17)$. Therapeutic approaches of FDCS vary significantly and include total surgical removal with or without adjuvant radio and/or chemotherapy or chemotherapy by itself.

\section{Case report}

A 66-year-old patient suffered from an otherwise asymptomatic suddenly arisen right cervical mass in December of 2001. Upon clinical examination he presented with a rounded well-relocatable submandibular tumour of about $2 \mathrm{~cm}$ in maximum diameter and underwent surgical resection in early 2002 alio loco (University Hospital Aachen, Germany). The tumour was completely removed and the specimen 
was diagnosed as a metastasis of a medium proliferative spindle-cell mesenchymal tumour to a cervical lymph node, for instance a fibrosarcoma or a nerve sheath tumour. After extensive subsequent screening of the patient for further metastases and a primary tumour was negative, the specimens were referred to the national reference centre for soft tissue tumours. Histopathologic re-evaluation revealed a relatively uniform aspect with balls and curls of tumour cells with a chromatin-rich, hardly definable cytoplasm reminiscent of a nerve sheath tumour (Fig. 1; H\&E micrographs). Immunohistochemistry confirmed the suspected diagnosis of a FDCS (Table I). In 2001 only few cases of FDCS were reported, most of them treated FDSC with total, local excision without adjuvant therapy (18-20). In some cases of FDCS occurring in multiple locations chemotherapy (alone or adjuvant) was performed $(20,21)$. Therefore, the patient was not subjected to any further therapy.

In June 2005 the patient was referred to our outpatient department (University Hospital Düsseldorf, Germany) with a right-sided submandibular nontender cervical lump of $2.5 \times 2.5 \mathrm{~cm}$ right beneath the scar of the former surgical approach. Again, the lesion was asymptomatic otherwise, and clinically there were no further pathologic findings. A contrast-enhanced CT scan (SOMATOM ${ }^{\circledR}$ Sensation 6-System; Siemens) raised the suspicion of a metastatic lymph node conglomerate in the right neck-region I B without evidence of a primary tumour. MRI (1,5 T Magnetom ${ }^{\circledR}$ Vision system; Siemens) demonstrated two cervical masses almost isointense with skeletal muscles on T1-weighted imaging, with a high signal intensity on T2-weighted images and only weakly enhanced on fat-suppressed contrast-enhanced T1-weigthed images obtained after administration of gadolinium-DTPA. Conventional B-scan-sonography of the region (Technos MPX System by Esaote ${ }^{\mathrm{TM}}$ ) showed four homogenous round masses of low echogenicity in the right submandibular region with a pathologic diffuse vascularisation pattern [Fig. 2; sonography in 2005-B-Mode and color doppler ultrasound using a linear (14-8 MHz)]. The size of the masses ranged from 11.3 to $18.3 \mathrm{~mm}$ in maximum diameter. Additionally, the lesions were investigated using power doppler-analysis, tissue-enhanced imaging (TEI), and contrast-enhanced phase inversion low MI $(<0-1)$ real-time ultrasound (CnTI) with the second-generation echo enhancer SonoVue ${ }^{\mathrm{TM}}(4.8 \mathrm{ml}$ as a bolus i.v. followed by $5 \mathrm{ml} \mathrm{NaCl}$ i.v.; Bracco Corp.) (Fig. 2; sonography in 2005). Unfortunately, there were no PET images taken. A PET-CT could have added further information.

Under the differential diagnosis of a recurrence of the FDC-Tumour versus a CUP-syndrome (carcinoma of unknown primary), the four masses were removed using the same submandibular approach as used in 2002, and again they appeared to be well-encapsulated and were removed macroscopically in toto. Histopathologic evaluation now revealed four tumours well defined by connective tissue consisting of spindle-shaped, less pleomorphic cells with a light prominent nucleus and grained chromatin (Fig. 1; H\&E micrographs).

Upon confirmation of the suspected diagnosis by a national referencecentre the patient was submitted toa restaging-program including CT-scans of the head and neck region, the chest, and the abdomen as well as a contrast-enhanced ultrasonographic examination of the abdominal organs. All investigations were negative for any other primary or metastatic disease. Again, the patient declined receiving any further therapy and was closely monitored.

In 2007 the patient presented once more with two enlarged lymph nodes both about $2.5 \times 2.1 \times 1.7 \mathrm{~cm}$ in size. One in the right submandibular region (IB), the other in the anterior submandibular region (IA) (Fig. 3; CT scans in 2007-Somatom Emotion 6 by Siemens Healthcare $\mathrm{GmbH}$ ). The lymph nodes were surgically removed and histologically investigated. Specimens showed cells matching the previously identified follicular dendritic cell sarcoma. Adjuvant radiotherapy and/or chemotherapy was offered but refused by the patient, because of its indefinite success (22), its side effects, and prolonged hospitalisation.

In 2008 the patient felt another submandibular mass growing. In addition, several slightly enlarged lymph nodes were found. Considering the quick recurrence and the involvement of several lymph nodes the patient agreed to receive systemic chemotherapy with a $\mathrm{CHOP}$ regimen. Nevertheless, to receive a second opinion, he transferred to another hospital (University Hospital Cologne, Germany), where a mass of $2 \times 2 \times 1.4 \mathrm{~cm}$ was identified sonographically and a tumour resection in combination with a neck dissection was performed in June of 2008. The pathohistological examination of the excised specimens was congruous with the previously described follicular dendritic cell sarcoma. No adjuvant therapy was performed. After close monitoring the patient has been recurrence-free for ten years.

Retrospectively (in 2018) samples from all operations (using formalin-fixed and paraffin-embedded archival samples from 2002, 2005, 2007, and 2008) were reevaluated immunohistochemically (Fig. 4; immunochemical micrographs; Table I; immunohistochemial results) and analysed by molecular pathology using next-generation sequencing (NGS). Immunohistochemical staining was performed according to standard procedures on a Leica Bond system (Leica Microsystems) using monoclonal antibodies directed against CD21 (clone 1F8, 1:50; Dako), CD23 (clone SP23, 1: 100; Thermo Fischer Scientific, Inc.), CD35 (clone LRB25, 1:25; Cell Marque), and PD-L1 (Clone 28-8, 1:100; Dako). For NGS six sections of $10 \mu \mathrm{m}$ thickness were cut from FFPE tissue blocks. Sections were deparaffinised and the tumour areas were macrodissected from unstained slides using a marked haematoxylin-eosin (H\&E) stained slide as a reference. After proteinase $\mathrm{K}$ digestion, the DNA was isolated with the Maxwell $^{\circledR} 16$ FFPE Plus Tissue LEV DNA purification kit (Promega) on the Maxwell ${ }^{\circledR} 16$ (Promega) following manufacturer's instructions. The DNA content was measured using quantitative PCR (qPCR).

For multiplex PCR-based target enrichment, the isolated DNA (10 ng each) was amplified with a customised GeneRead DNAseq Targeted Panel V2 (Qiagen) and the GeneRead DNAseq Panel PCR kit V2 (Qiagen) according to the GeneRead DNASeq Gene Panel handbook (Qiagen). The custom panel comprised a subset of cancer relevant genes including: BRAF, CDK4, CDKN2A, GNA11, GNAQ, HRAS, IDH1, KIT, KNSTRN, KRAS, NRAS, OXA1L, PDGFRA, PIK3CA, PTEN, RAC1 and TP53.

Libraries were constructed using the Gene Read DNA Library I Core kit and the Gene Read DNA I Amp kit (Qiagen). After end-repair and adenylation, NEXTflex DNA Barcodes 
Table I. Immunohistochemical results.

\begin{tabular}{|c|c|c|c|c|}
\hline Marker & 2002 & 2005 & 2007 & 2008 \\
\hline $\mathrm{CD} 23$ & +++ & +++ & +++ & +++ \\
\hline $\mathrm{CD} 21$ & +++ & +++ & +++ & +++ \\
\hline CD35 & - & - & + & - \\
\hline PD-L1 & - & - & - & - \\
\hline D2-40 & +++ & +++ & +++ & +++ \\
\hline CD68 & + & + & + & + \\
\hline EMA & - & + & + & - \\
\hline Vimentin & +++ & +++ & +++ & +++ \\
\hline $\mathrm{S} 100$ & 1 & - & 1 & 1 \\
\hline CK & 1 & - & 1 & 1 \\
\hline Mib-1 (in hot spot areas), $\%$ & 30 & 45 & 30 & 40 \\
\hline
\end{tabular}

,- negative; + , partially positive; +++ , positive.

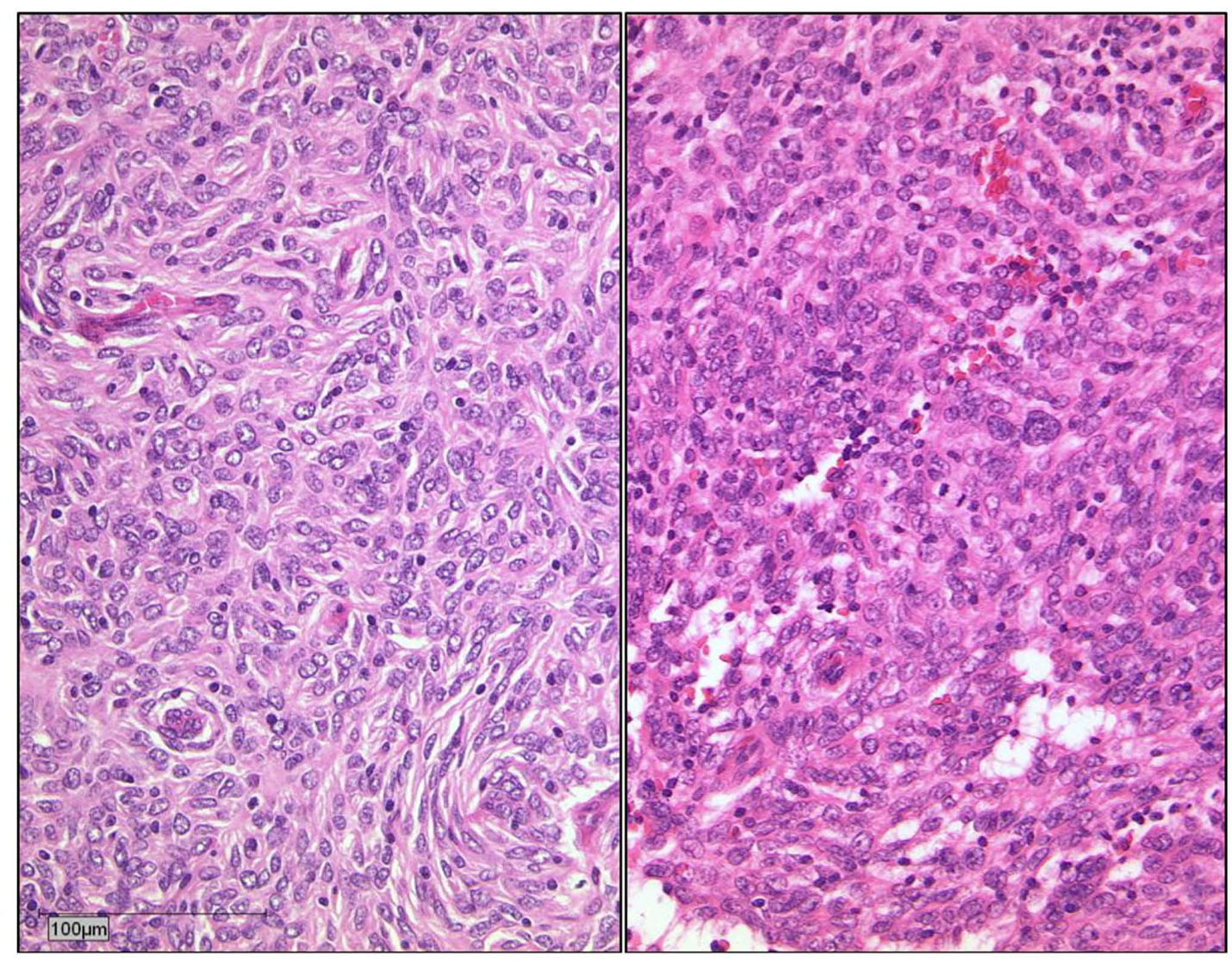

Figure 1. H\&E micrographs. H\&E staining in 2002 (left) showing balls and curls of tumour cells with a chromatin-rich, hardly definable cytoplasm, and in 2007 (right) showing spindle-shaped, less pleomorphic cells with a light prominent nucleus and grained chromatin. Magnification, x20. H\&E, haematoxylin and eosin.

were ligated (Bio Scientific). Barcoded libraries were amplified and then the final library product was quantified with QuantiFluor dsDNA System (Promega) on the Quantus Fluorometer (Promega), diluted and pooled in equal amounts. Finally, $12 \mathrm{pM}$ of the constructed libraries were sequenced on the MiSeq (Illumina) with a MiSeq reagent kit V2 (300-cycles; Illumina) following the manufacturer's recommendations.

Data were exported as FASTQ files. Alignment and annotation was done using a modified version of a previ- ously described method (23). BAM files were visualised in the Integrative Genomics viewer (http://www.broadinstitute. org/igv/). A 5\% cut-off for variant calls was used and results were only interpreted if the coverage was $>200 x$.

\section{Discussion}

Because of the rarity of FDCS, there is no standardized or even guideline-based treatment of the tumour. Therefore, treatment 


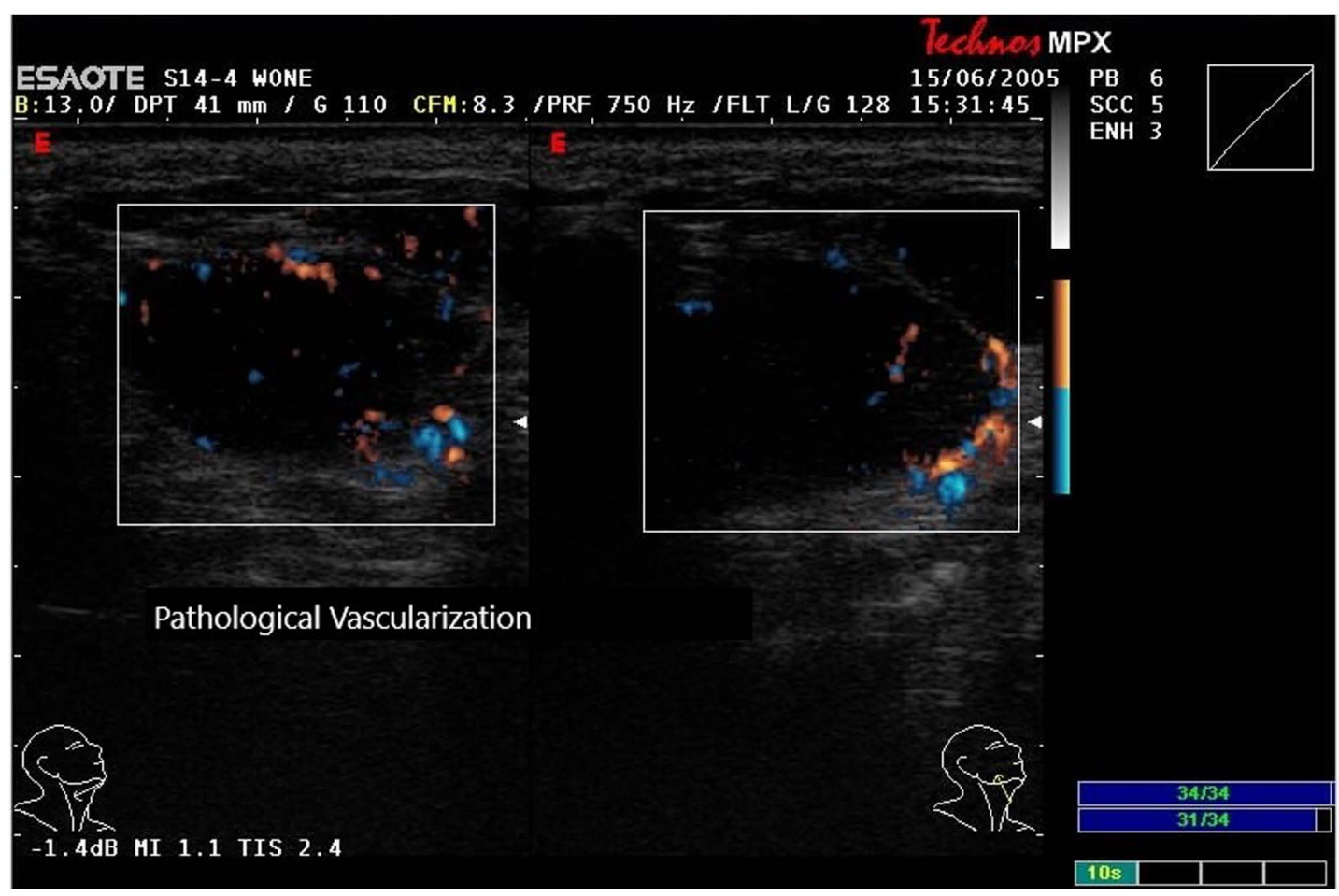

Figure 2. Sonography in 2005. B-Mode and color Doppler ultrasound using a linear (14-8 MHz) transducer revealed four round hypoechoic lesions (of up to $20 \mathrm{~mm}$ in maximum diameter) in the right submandibular region (IB) with dorsal sound reinforcement indicative of a high cell content of the tumour. The vascularization pattern is characterized by multiple feeders and chaotic intranodal vascular branching indicative of a malignant process.
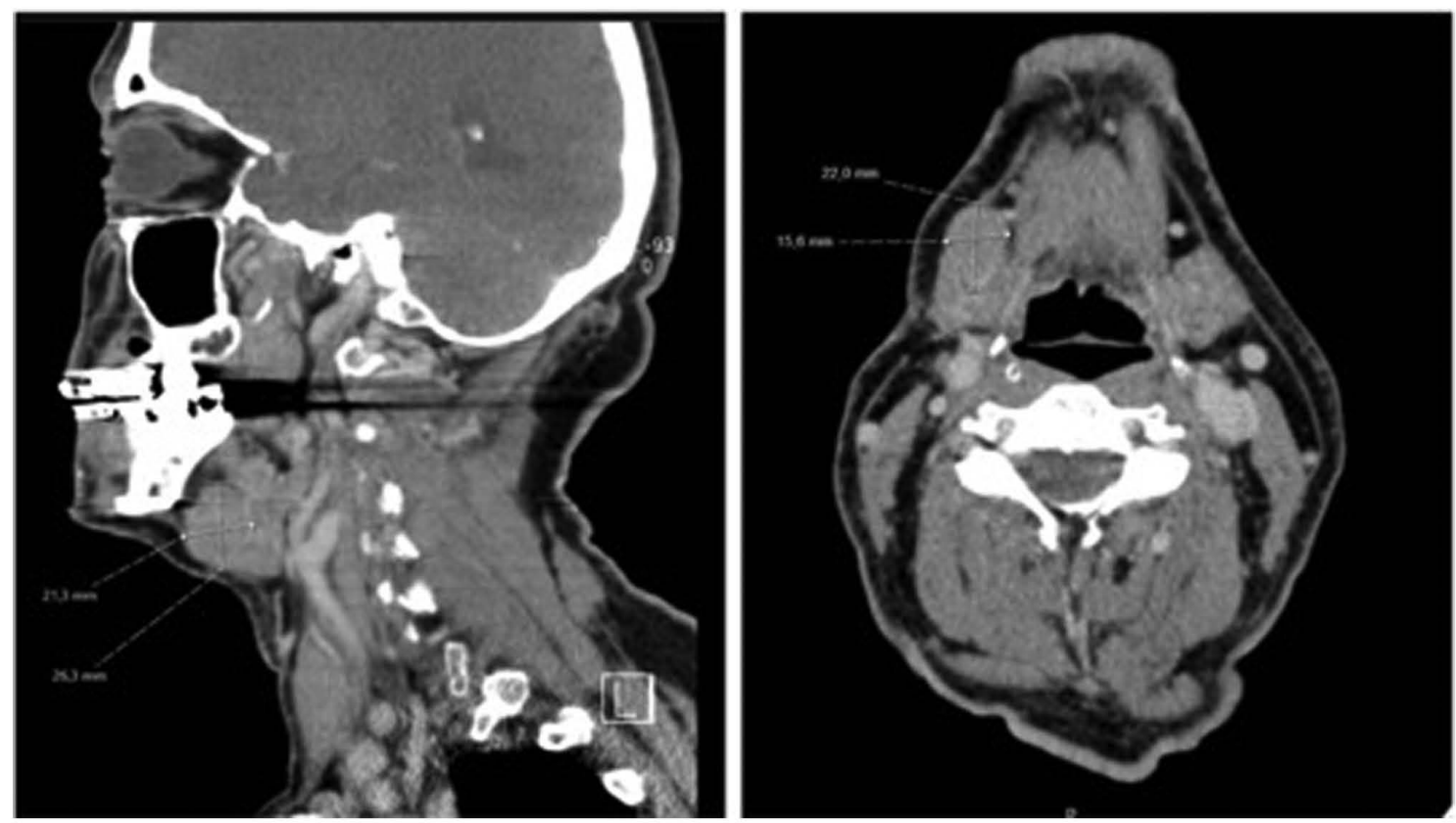

Figure 3. CT scans in 2007. High resolution $(2 \mathrm{~mm}$ ) computed tomography in the sagittal (left) and the axial (right) planes are shown. A $2.5 \times 2.1 \times 1.7 \mathrm{~cm}$ big mass in level $\mathrm{lb}$ adjacent to the right submandibular gland could be found.

modalities can differ significantly. Depending on its supposed origin (stromal or lymphoid) the tumour is treated differently.

On the one hand FDCS is treated similar to sarcoma by surgery. Surgical excision has proven successful in unilocular FDCS (18-20) Amin at al. for example reported a case of FDCS of the head and neck which was treated by surgical excision. No neck dissection was performed. Their patient showed no recurrence after two years (12). Surgery in combination with adjuvant chemo- or radiotherapy has also been attempted in cases of multilocular FDCS $(20,21)$. Pisani et al (24), treated FDCS of the head and neck by surgical excision and five courses of adjuvant chemotherapy with COP plus (PEG)-liposomal doxorubicin. Nevertheless, in localised FDCS adjuvant treatment showed no significant effect on overall survival (22). 


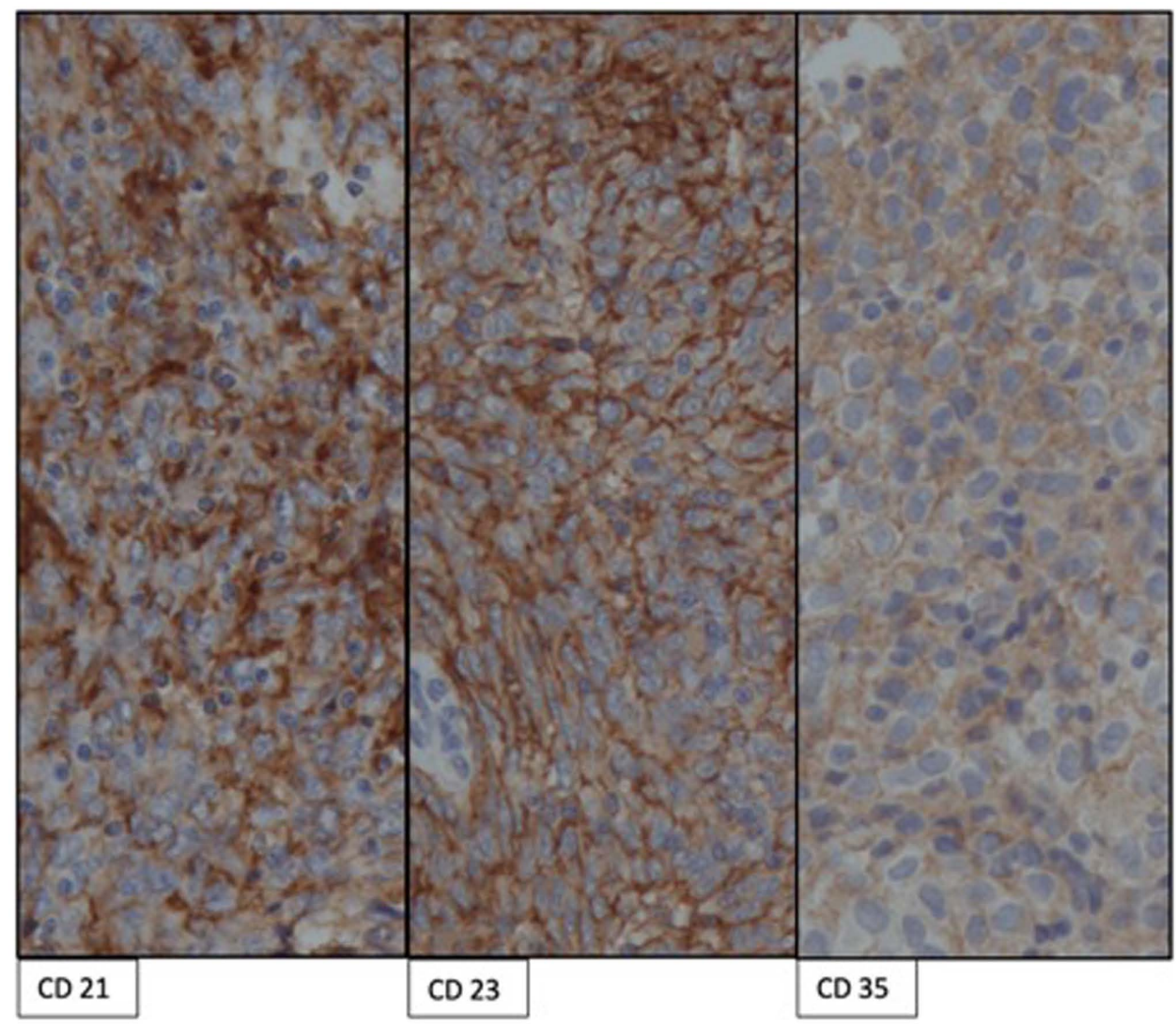

Figure 4. Immunochemical micrographs. CD21+, CD23+ and CD35- immunochemical results in 2007. Magnification, x20.

On the other hand FDCS is treated like lymphoid tumours by chemotherapy with cyclophosphamide, doxorubicin, vincristine, and prednisone (CHOP) or CHOP-like regimens. As immunotherapeutial and chemotherapeutical options increase due to advances in research and technology, there are more therapeutic attempts coming from this field. Choi et al (13), reported a case of FDCS in which the patient was treated with a CHOP regimen. The outcome was a partial response after two cycles. High recurrence rates could be a result of not yet elaborated regimens. Roesch et al (25), for example hypothesized in 2014 that intensive chemotherapies lead to a depletion of immune cells allowing an early regrowth of the tumour.

Our patient tested positive for CD21, CD23, D2-40 and Vimentin, partially positive for CD68, and negative for CD35 (except in 2007) in every sample taken (Table I). This indicates an apparently low evolution of the tumour over a long period of time. In NGS no somatic mutation was detected, all genes were wild type. This combination could be specific for a locally less aggressive and only slowly progressive tumour with a low malignant potential. Furthermore, it might indicate a high recurrence rate. Our case is unique because although there were many recurrences (indeed, this many recurrences in one patient haven't been described before) in different locations of the neck, the patient refused to obtain any treatment other than surgery. This case raises the question whether the excisions left behind vital tumour tissue giving raise to the recurrences or if there is some kind of local (micro-) metastasis in lymph nodes occurring in FDCS causing further spread. After the 4th recurrence a compre- hensive neck dissection was performed. Following that, the patient has been recurrence-free for over ten years. A more extensive surgical approach might therefore, in the individual case, prevent regrowth and can lead to a full recovery even in multiple recurrences.

Molecular technologies like whole transcriptome sequencing (WTS) have not only revealed new markers for FDC, such as FDCSP or serglycin (26), but they also might open the door to definitively clear the histogenesis of FDCs and to study the immunological microenvironment (27). Those techniques are expected to lead to new targeted drug therapies for FDCS in the future. Even though it might be challenging, research has to be continued in order to fully understand the function and progenitors of follicular dendritic cells. Only if FDCs are fully understood, a way for adequate therapy for FDC Sarcoma can be developed.

\section{Acknowledgements}

Not applicable.

\section{Funding}

No funding was received.

\section{Availability of data and materials}

The datasets used and/or analysed during the present study are available from the corresponding author on reasonable request. 


\section{Authors' contributions}

LS wrote the manuscript. JL, NK, MR and RD revised the manuscript critically. $\mathrm{CH}$ and PL performed and interpreted the histopathological and immunohistochemical staining in 2018. PK was involved in the earlier histopathological and immunohistochemical staining. CS collected samples, performed sonographies, was the leading surgeon and had the idea to publish this case. All authors read and approved the final manuscript.

\section{Ethics approval and consent to participate}

Not applicable.

\section{Patient consent for publication}

Written informed consent was obtained.

\section{Competing interests}

The authors declare that they have no competing interests.

\section{References}

1. van Nierop $\mathrm{K}$ and de Groot $\mathrm{C}$ : Human follicular dendritic cells: Function, origin and development. Semin Immunol 14: 251-257, 2002.

2. Jarjour M, Jorquera A, Mondor I, Wienert S, Narang P, Coles MC Klauschen $\mathrm{F}$ and Bajénoff $\mathrm{M}$ : Fate mapping reveals origin and dynamics of lymph node follicular dendritic cells. J Exp Med 211: $1109-1122,2014$

3. Aguzzi A, Kranich J and Krautler NJ: Follicular dendritic cells: Origin, phenotype, and function in health and disease. Trends Immunol 35: 105-113, 2014.

4. Cyster JG, Ansel KM, Reif K, Ekland EH, Hyman PL, Tang HL, Luther SA and Ngo VN: Follicular stromal cells and lymphocyte homing to follicles. Immunol Rev 176: 181-193, 2000.

5. Allen CD and Cyster JG: Follicular dendritic cell networks of primary follicles and germinal centers: Phenotype and function. Semin Immunol 20: 14-25, 2008.

6. Wang X, Cho B, Suzuki K, Xu Y, Green JA, An J and Cyster JG: Follicular dendritic cells help establish follicle identity and promote B cell retention in germinal centers. J Exp Med 208: 2497-2510, 2011.

7. Bajénoff M, Egen JG, Koo LY, Laugier JP, Brau F, Glaichenhaus N and Germain RN: Stromal cell networks regulate lymphocyte entry, migration, and territoriality in lymph nodes. Immunity 25 : 989-1001, 2006.

8. Ansel KM, Ngo VN, Hyman PL, Luther SA, Förster R Sedgwick JD, Browning JL, Lipp $M$ and Cyster JG: A chemokine-driven positive feedback loop organizes lymphoid follicles. Nature 406: 309-314, 2000

9. Usui K, Honda S, Yoshizawa Y, Nakahashi-Oda C, Tahara-Hanaoka S, Shibuya $\mathrm{K}$ and Shibuya $\mathrm{A}$ : Isolation and characterization of naïve follicular dendritic cells. Mol Immunol 50: 172-176, 2012.

10. Muñoz-Fernández R, Blanco FJ, Frecha C, Martín F, Kimatrai M, Abadía-Molina AC, García-Pacheco JM and Olivares EG: Follicular dendritic cells are related to bone marrow stromal cell progenitors and to myofibroblasts. J Immunol 177: 280-289, 2006.
11. Monda L, Warnke R and Rosai J: A primary lymph node malignancy with features suggestive of dendritic reticulum cell differentiation. A report of 4 cases. Am J Pathol 122: 562-572, 1986.

12. Amin Z, Suhaimi Y and Ahmad R: Head and neck follicular dendritic cell sarcoma: Disease associations and treatment review. Med J Malaysia 65: 77-79, 2010.

13. Choi BS, Baek JH, Shin YM, Kim JH, Kim HW, Lee SJ and Cha HJ: Follicular dendritic cell sarcoma: A case report and review of the literature. Cancer Res Treat 42: 121-124, 2010.

14. Chan JK, Fletcher CD, Nayler SJ and Cooper K: Follicular dendritic cell sarcoma. Clinicopathologic analysis of 17 cases suggesting a malignant potential higher than currently recognized. Cancer 79: 294-313, 1997.

15. Vermi W, Lonardi S, Bosisio D, Uguccioni M, Danelon G, Pileri S, Fletcher C, Sozzani S, Zorzi F, Arrigoni G, et al: Identification of CXCL13 as a new marker for follicular dendritic cell sarcoma. J Pathol 216: 356-364, 2008.

16. Krautler NJ, Kana V, Kranich J, Tian Y, Perera D, Lemm D, Schwarz P, Armulik A, Browning JL, Tallquist M, et al: Follicular dendritic cells emerge from ubiquitous perivascular precursors. Cell 150: 194-206, 2012.

17. El Shikh ME, El Sayed RM, Sukumar S, Szakal AK and Tew JG: Activation of B cells by antigens on follicular dendritic cells. Trends Immunol 31: 205-211, 2010.

18. Han JH, Kim SH, Noh SH, Lee YC, Kim HG and Yang WI: Follicular dendritic cell sarcoma presenting as a submucosal tumor of the stomach. Arch Pathol Lab Med 124: 1693-1696, 2000.

19. Katano H, Kaneko K, Shimizu S, Saito T, Irié T and Mori S: Follicular dendritic cell sarcoma complicated by hyaline-vascular type Castleman's disease in a schizophrenic patient. Pathol Int 47: 703-706, 1997.

20. Perez-Ordonez B, Erlandson RA and Rosai J: Follicular dendritic cell tumor: Report of 13 additional cases of a distinctive entity. Am J Surg Pathol 20: 944-955, 1996.

21. Toyoda K, Taniguchi J, Kikawa K, Uike N, Haraoka S, Ooshima K, Kikuchi M and Kawanishi H: Follicular dendritic cell sarcoma: Ultrastructural and immunohistochemical studies. Intern Med 39: 950-955, 2000.

22. Chow SC, Yeung EC, Ng CS, Wong RH, Fai To K and Wan IY: Mediastinal follicular dendritic cell sarcoma with paraneoplastic pemphigus. Asian Cardiovasc Thorac Ann 23: 732-734, 2015.

23. Peifer M, Fernández-Cuesta L, Sos ML, George J, Seidel D, Kasper LH, Plenker D, Leenders F, Sun R, Zander T, et al: Integrative genome analyses identify key somatic driver mutations of small-cell lung cancer. Nat Genet 44: 1104-1110, 2012.

24. Pisani F, Marino M, Sentinelli S and Petti MC: Follicular dendritic cell sarcoma of the neck: Report of a case treated by surgical excision and COP plus (PEG)-liposomal doxorubicin. J Exp Clin Cancer Res 27: 33, 2008.

25. Roesch K, Hasenclever D and Scholz M: Modelling lymphoma therapy and outcome. Bull Math Biol 76: 401-430, 2014.

26. Lorenzi L, Döring C, Rausch T, Benes V, Lonardi S, Bugatti M, Campo E, Cabeçadas J, Simonitsch-Klupp I, Borges A, et al: Identification of novel follicular dendritic cell sarcoma markers, FDCSP and SRGN, by whole transcriptome sequencing. Oncotarget 8: 16463-16472, 2017.

27. Laginestra MA, Tripodo C, Agostinelli C, Motta G, Hartmann S, Döring C, Rossi M, Melle F, Sapienza MR, Tabanelli V, et al: Distinctive histogenesis and immunological microenvironment based on transcriptional profiles of follicular dendritic cell sarcomas. Mol Cancer Res 15: 541-552, 2017. Attribution-NonCommercial-NoDerivatives 4.0 International (CC BY-NC-ND 4.0) License. 